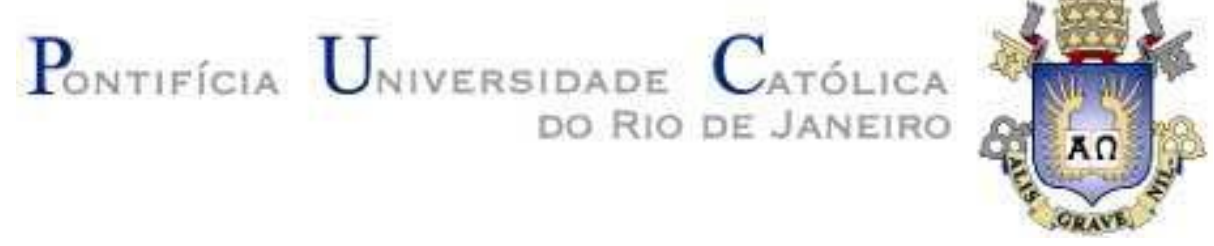

Eduardo Ribeiro Alves Barboza Vianna

Relação Risco, Retorno e Liquidez na Construção de Portfólios de Fundos de Fundos

Dissertação de Mestrado

Dissertação apresentada ao Programa de PósGraduação em Administração da PUC-Rio como requisito parcial para obtenção do título de Mestre em Administração de Empresas.

Orientador: Prof. Luiz Felipe Jacques da Motta 


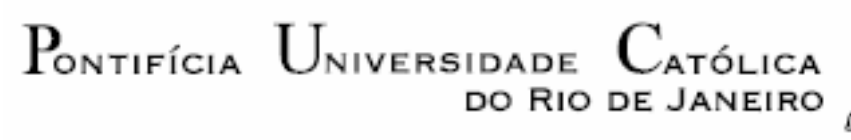

Eduardo Ribeiro Alves Barboza Vianna

\title{
Relação Risco, Retorno e Liquidez na Construção de Portfólios de Fundos de Fundos
}

\begin{abstract}
Dissertação apresentada como requisito parcial para obtenção do grau de Mestre pelo Programa de Pósgraduação em Administração da PUC-Rio. Aprovada pela Comissão Examinadora abaixo assinada.
\end{abstract}

Prof. Luiz Felipe Jacques da Motta

Orientador

Departamento de Administração - PUC-Rio

Prof. Marcelo Cabus Klotzle

Departamento de Administração - PUC-Rio

Profa $^{\text {. Kátia Rocha }}$

IPEA

Prof. Nizar Messari

Vice-Decano de Pós-Graduação do CCS

Rio de Janeiro, 27 de março de 2008 
Todos os direitos reservados. É proibida a reprodução total ou parcial do trabalho sem autorização da universidade, do autor e do orientador.

\section{Eduardo Ribeiro Alves Barboza Vianna}

Graduou-se em Engenharia Mecânica e Produção Mecânica em 2000 na Pontifícia Universidade Católica do Rio de Janeiro. Em 2002, graduou-se também em Engenharia Civil. Passou alguns anos dedicados à incorporação imobiliária e atualmente trabalha com gestão financeira.

Ficha Catalográfica

Vianna, Eduardo Ribeiro Alves Barboza

Relação risco, retorno e liquidez na construção de portfólios de fundos de fundos / Eduardo Ribeiro Alves Barboza Vianna ; orientador: Luiz Felipe Jacques da Motta. - 2008.

76 f. : il.(col.) ; $30 \mathrm{~cm}$

Dissertação (Mestrado em Administração)Pontifícia Universidade Católica do Rio de Janeiro, Rio de Janeiro, 2008.

Inclui bibliografia

1. Administração - Teses. 2. Fundo de fundos. 3. Risco. 4. Retorno. 5. Liquidez. 6. Autocorrelação. 7. Fundos de investimento. I. Motta, Luiz Felipe Jacques da. II. Pontifícia Universidade Católica do Rio de Janeiro. Departamento de Administração. III. Título. 
Aos meus pais, pelo apoio incondicional em todas as horas, e a minha esposa Daniela pelo amor e certeza de nossa eterna felicidade. 


\section{Agradecimentos}

À minha esposa Daniela pela compreensão, dedicação e ajuda.

À minha família pelo apoio e incentivo ao longo do curso.

Ao meu orientador Professor Luiz Felipe Motta pela atenção e presteza na realização deste trabalho.

Aos professores do departamento de Administração da PUC-Rio que participaram da minha formação.

E aos funcionários do Departamento de Administração da PUC-Rio pela solicitude e paciência. 


\section{Resumo}

Vianna, Eduardo Ribeiro Alves Barboza; Motta, Luiz Felipe. Relação Risco, Retorno e Liquidez na Construção de Portfólios de Fundos de Fundos. Rio de Janeiro, 2008. 76p. Dissertação de Mestrado Departamento de Administração, Pontifícia Universidade Católica do Rio de Janeiro.

O universo de hedge funds cresce a taxas aceleradas no Brasil já há alguns anos e vem, à medida que os juros caem, conquistando investidores que restringiam suas aplicações à renda fixa tradicional. Um outro segmento da indústria financeira vem a reboque, são os fundos de fundos. O objetivo deste trabalho é propor uma metodologia quantitativa para auxiliar na construção de portfólios de fundos de fundos que vai além do tradicional modelo de médiavariância. Será incluída uma terceira variável na avaliação dos portfólios, o risco de liquidez. Para isso, será usado como base o estudo "Dyanmics of the Hedge Fund Industry" do Professor Andrew W. Lo do MIT Sloan School of Management (2005). A indústria de hedge funds será dividida em diversos segmentos em função das estratégias utilizadas e em seguida, avaliaremos quais as combinações de estratégias oferecem a melhor relação Risco, Retorno e Liquidez para o investidor.

\section{Palavras-chave}

Fundo de Fundos; risco; retorno; liquidez; autocorrelação; fundos de investimento. 


\section{Abstract}

Vianna, Eduardo Ribeiro Alves Barboza; Motta, Luiz Felipe (Advisor). Return, Risk e Liquidity Relationship in Funds of Funds Portfolio Construction. Rio de Janeiro 2008. 76p. MSc. Dissertation - Departamento de Administração, Pontifícia Universidade Católica do Rio de Janeiro.

During the recent years, hedge funds in Brazil experienced an incredible increase in assets under management. Many investors are changing their asset allocation, migrating from fixed income to hedge funds. With this movement, another segment of the same industry will flourish: Funds of funds. This work main objective is to propose a methodology to help on the portfolio construction of funds of funds based not only on the relationship return and risk, but including a new parameter, liquidity. This work is based on the study "Dynamics of the Hedge Fund Industry” by Professor Andrew W. Lo from the MIT Sloan School of Management (2005). In order to do so, the Brazilian hedge fund industry will be divided based on the strategies used on their investments, and then an optimization process will sort out the portfolios that offer the best Return, Risk and Liquidity combination for investors.

\section{Keywords}

Fund of funds; risk; return; liquidity; autocorrelation; investment funds 


\section{Sumário}

1. Introdução 11

1.1. Apresentação 11

1.2. Objetivos 13

1.3. Delimitações do Estudo 14

1.4. Relevância do Estudo 15

2. Referencial Teórico 16

2.1. Hedge Funds 16

2.2. Índices de Hedge Funds 20

2.3. Propriedades dos Índices de Hedge Funds 24

2.4. Autocorrelação e Iliquidez $\quad 27$

3. Metodologia 30

3.1. Tipo de Pesquisa 30

3.2. Universo e Amostra 31

3.3. Coleta de Dados $\quad 35$

3.4. Tratamento de Dados 36

3.4.1. Preparação dos Dados e Comparação entre os Índices Utilizados $\quad 36$

3.4.2. Teste Estatístico para Autocorrelação dos Índices 37

3.4.3. Definição da Métrica de Liquidez para os Portfolios 37

3.4.4. Construção de Portfolios de Hedge Funds com Restrições de
Liquidez

3.5. Limitações do Estudo 39

4. Desenvolvimento e Análise dos Resultados 40

4.1. Propriedades dos Índices 41

4.2. Comparação dos Índices 42

4.3. Cálculo de Liquidez 45

4.4. Construção dos Portfolios com Restrições de Liquidez 49

4.5. Análise dos Portfolios 53

4.6. Exemplo $\quad 55$

5. Considerações Finais $\quad 57$

6. Referências Bibliográficas 60

7. Anexos $\quad 62$

7.1. Anexo 1 - Regulamento dos Índices Arsenal 62

7.2. Anexo 2 - Relação dos fundos que compõem os índices Arsenal 71 


\section{Lista de tabelas}

Tabela 1 - Classificação ANBID de Fundos de Investimento Multimercado 19

Tabela 2 - Equivalência de classificações de estratégias 24

Tabela 3 - Propriedades Estatísticas dos Índices da CSFB/Tremont, retornos mensais Jan/94 - Ago/04 25

Tabela 4 - Matriz de Correlação para os Índices CSFB/Tremont para retornos mensais, Jan/94-Ago/04 26

Tabela 5 -Dados Estatísticos Mensais dos Índices Arsenal 41

Tabela 6 - Dados Estatísticos Mensais dos Índices de Mercado 41

Tabela 7 - Resultados Teste Normalidade para Dados Mensais 43

Tabela 8 - Resultados Teste de Normalidade para Dados Diários 43

Tabela 9 - Resultados Teste de Comparação das Distribuições 44

Tabela 10 - Resultados das Autocorrelações $\quad 45$

Tabela 11 - Matriz de Correlação entre os Índices (Dados Diários) 46

Tabela 12 - Matriz de Correlação entre os Índices (Dados Mensais) 47

Tabela 13 - Índices divididos por faixas de liquidez 48

Tabela 14 - Propriedades dos Portfolios com Sharpe Máximo 53 


\section{Lista de figuras}

Figura 1 - Evolução da Participação dos Fundos Multimercados $\begin{array}{ll}\text { no Mercado Brasileiro } & 18\end{array}$

Figura 2 - Possibilidades de classificação para hedge funds 20

Figura 3 - Fronteiras eficientes com restrições de liquidez 50

Figura 4 - Fronteira de Índices de Sharpe x Liquidez 51

Figura 5 - Derivada do Índice de Sharpe em relação a Liquidez 52

Figura 6 - Composição dos Portfolios 53 